\title{
Modeling and Simulation of Electrical Resonance in EHV Transmission Line Case Study in West Java Region 500 kV System
}

\author{
Putu Agus Aditya Pramana ${ }^{1, a}$, Buyung Sofiarto Munir ${ }^{1}$ \\ ${ }^{1}$ PLN Indonesia, Transmission and Distribution Research Group, Jakarta, Indonesia
}

\begin{abstract}
Electrical transmission line can be approached by the second order system with the model of capacitive, inductive, and resistive elements. In the system, the capacitive element is represented by the capacitance value between phases and phase to ground. In the other side, inductance of reactor and phase conductor represent the inductance element, whereas resistance of the phase conductor represents the resistance value of the system. As a second order system, the electrical transmission line is potentially experiencing the resonance phenomena if the natural frequency reaches the $50 \mathrm{~Hz}$ operation frequency. This paper explains the study of resonance phenomena in Extra High Voltage (EHV) $500 \mathrm{kV}$ transmission line between two 500 $\mathrm{kV}$ Substation in West Java Region by the modeling and simulation. The results show that the transmission line is very vulnerable to the resonance phenomenon which is indicated by the existence of voltage up to $800 \mathrm{kV}$ when this transmission line is not yet energized and causing one of the line arrester broken. The results also show that under the resonance phenomena, single pole auto reclose process is potentially failed. This study is expected to increase the concern for the resonance phenomena in the transmission lines.
\end{abstract}

\section{Introduction}

Substation B is a new $500 \mathrm{kV}$ extra high voltage (EHV) substation which is located between substation A and the substation C. Substation A is separated about $304 \mathrm{~km}$ to the Substation C, whereas Substation B intersects the line about $105 \mathrm{~km}$ from Substation A, and the first transpose point is located about $101 \mathrm{~km}$ from Substation A. EHV Transmission lines from Substation A to Substation $\mathrm{C}$ consist of two lines, line I and line II as shown in figure 1(a). Most of tower design which is used in this transmission lines are shown in figure 1(b). From the figure 1(b) we can find the dimension of the tower, the distance between the phase conductors, and the distance of phase conductors to the ground. Substation B is an EHV Substation with a $1 \frac{1 / 2}{2}$ breaker system. Currently, Substation B intersects transmission line I from Substation A to Substation C only, while the transmission line II from Substation A to Substation C just pass through Substation B.

Prior to the energize process in substation B, Earthing Switch (ES) in Substation B still on the closed position, a moment later the ES was opened and then the disconnecting switch (DS) in both side Substation B and Substation A were closed. In this condition, the reactors in line I Substation A were still opened and the induction voltages on line I Substation B arose which have value about 28

\footnotetext{
${ }^{\mathrm{a}}$ Corresponding author : putu.agus.tf@gmail.com
} 
$\mathrm{kV}$ for phase R-N, $19 \mathrm{kV}$ for phase S-N, and $12 \mathrm{kV}$ for phase T-N. On the further step, the reactors for line I in Substation A were closed for each phase and unexpectedly the voltages for each phase in this line increased significantly to the $261 \mathrm{kV}$ for phase R-N, $44 \mathrm{kV}$ for phase $\mathrm{S}-\mathrm{N}$, and $235 \mathrm{kV}$ for phase $\mathrm{T}-\mathrm{N}$, moreover for a moment the voltage phase value reached $800 \mathrm{kV}$ which is suspected due the electrical resonance in EHV transmission line I Substation A to Substation B.

Related to this study, there are some researchers who have been published the paper about electrical transmission line, electromagnetic and resonance phenomena. [1] explained about the transient process on reactors with controlled and uncontrolled switching process. They did the calculation process and propose the mitigation for measures and operating switching strategy of variable shunt reactor. [2] described about the ferroresonance modelling on transformer. Based on EMTP simulation and field tests data, they explained that unload transformer possible to affect the ferroresonance. [3] described the methods to find the capacitance and inductance value for transmission line by the interactions of each phase conductor to the others. They found that both results from finite element analysis and analytical methods are within reasonable agreement to each other. [4] explained about the electrical resonance due to Power Factor correction (PFC)/VAR compensation which affects the harmonic value of the electrical wave. [5] studied the harmonics and resonances within the wind power plants which included an introduction to series and parallel resonances, frequency scan analysis, and the harmonic source characteristics of wind turbine generator and of utility interconnections. [6] described about the ferroresonance in distribution system. [7] studied the transients of reactor when energized and de- energized process and found that reactor imposed heavy duty on circuit breaker. [8] described the process of electrical resonance in the transmission line and how to solve the problem. [9] studied the ferroresonance in voltage transformer and found that instant switching and capacitance value affect the ferroresonance.

This study focused on electrical resonance phenomena for the EHV Transmission line from Substation A to Substation B which is include the modelling and simulation, and then describe the electrical resonance effect on the auto reclose process.

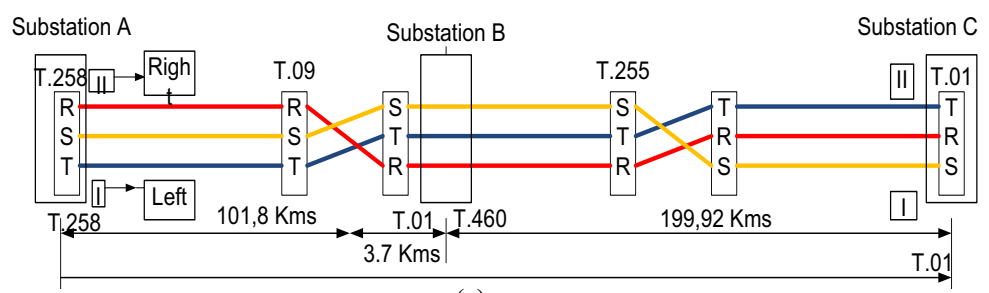

(a)

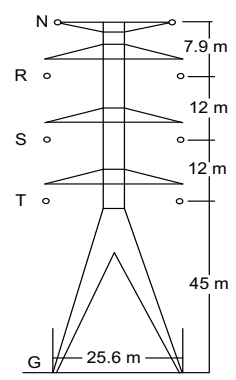

(b)

Figure 1. (a) Description of EHV Transmission Line from Substation A to Substation C, (b) Tower model for EHV Transmission line from Substation A to Substation B

\section{Modeling}

EHV Transmission line from Substation A to Substation B can be modelled using the capacitive, inductive and resistive elements as second order system that has natural frequency characteristic. The primary capacitance element of the transmission line model is the capacitance between the phases conductors and the capacitance between the phases to the ground. The primary inductance element for the model is the reactors for each phase which is located on Substation A and the inductance for the phase conductor, while the primary resistance element is the resistance of the phase conductor.

\subsection{Model Assumptions}


The modelling process has some assumptions to study the electrical resonance effect in the EHV transmission line. The assumptions are the EHV transmission lines from Substation A to Substation B assumed has the horizontal contour therefore the line tower can be modelled as figure 1(b), the effect conductor sagging is neglected, modelling process limited to the EHV transmission line Substation A to Substation B with type pi model, and the last one the transpose effect is included in the model.

\subsection{Model Properties}

The model described the two lines from Substation A to Substation B which each line consists of 3 phase and 4 wire transmission system. Interaction of each conductor phase and the conductor phase to the ground were modelled as capacitance values which given by the Equation 1 [3]. Equation 1 explained that the capacitance value of transmission system is affected by the dimension of the conductor phase, and the separated distance of the conductors. In the equations (1) to (3), C is capacitance per meter $(\mathrm{F} / \mathrm{m}), \mathrm{d}$ is the distance between conductors, $\mathrm{r}$ is the radius of conductor, $\mathcal{E}$ is the air permittivity, $\mathrm{L}$ is inductance per meter $(\mathrm{H} / \mathrm{m}), \mathrm{D}$ is distance between conductor, $R$ is resistance $(\mathrm{Ohm}), \mathrm{R}$ is first phase, $\mathrm{S}$ is second phase, $\mathrm{T}$ is third phase, $\mathrm{A}$ is conductor area, $\rho$ is resistivity, 1 is line $\mathrm{I}, 2$ is line II, 1 is conductor length, and $\mathrm{r}$ is conductor radius.

$$
\begin{gathered}
\mathrm{C}=\frac{\pi \varepsilon}{\ln \left(\frac{\mathrm{d}}{\mathrm{r}}\right)} \\
L=2 x 10^{-7} \ln \left[\sqrt[3]{D_{R S^{\prime} D_{R T^{\prime}} D_{S T^{\prime}}}} /\left(\sqrt{r e^{-\frac{1}{4}}} \cdot \sqrt[6]{D_{R 1 R 2} D_{S 1 S 2} D_{T 1 T 2}}\right)\right] \\
\mathrm{D}_{\mathrm{RS}}=\sqrt[4]{\mathrm{D}_{\mathrm{R} 1 \mathrm{~S} 1} \mathrm{D}_{\mathrm{R} 1 \mathrm{~S} 2} \mathrm{D}_{\mathrm{R} 2 \mathrm{~S} 1} \mathrm{D}_{\mathrm{R} 2 \mathrm{~S} 2}}, \mathrm{D}_{\mathrm{RT}}=\sqrt[4]{\mathrm{D}_{\mathrm{S} 1 \mathrm{~T} 1} \mathrm{D}_{\mathrm{S} 1 \mathrm{~T} 2} \mathrm{D}_{\mathrm{S} 2 \mathrm{~T} 1} \mathrm{D}_{\mathrm{S} 2 \mathrm{~T} 2}}, \mathrm{D}_{\mathrm{ST}}=\sqrt[4]{\mathrm{D}_{\mathrm{R} 1 \mathrm{~T} 1} \mathrm{D}_{\mathrm{R} 1 \mathrm{~T} 2} \mathrm{D}_{\mathrm{R} 2 \mathrm{~T} 1} \mathrm{D}_{\mathrm{R} 2 \mathrm{~T} 2}} \\
R=\rho \frac{\mathrm{A}}{\mathrm{A}}
\end{gathered}
$$

Table 1. Capacitance Model Value

\begin{tabular}{|c|c|c|c|c|c|}
\hline Line & $\begin{array}{c}\text { Capacitance values } \\
\text { from Substation A } \\
\text { to first transpose } \\
\text { (uF) }\end{array}$ & $\begin{array}{c}\text { Capacitance values } \\
\text { from first } \\
\text { transpose to } \\
\text { Substation B (uF) }\end{array}$ & Line & $\begin{array}{c}\text { Capacitance } \\
\text { values from } \\
\text { Subs tation A to } \\
\text { first trans pose }\end{array}$ & $\begin{array}{c}\text { Capacitance values } \\
\text { from first } \\
\text { transpose to } \\
\text { Substation B (uF) }\end{array}$ \\
\hline Phase T1-S1 & 0.1513 & 0.0047 & Phase R1-T2 & 0.1289 & 0.0040 \\
\hline Phase S1-R1 & 0.1513 & 0.0047 & Phase R1-S2 & 0.1329 & 0.0041 \\
\hline Phase R1-T1 & 0.1361 & 0.0042 & Phase R1-R2 & 0.1898 & 0.0049 \\
\hline Phase R1-G & 0.1084 & 0.0033 & N1- Phase-R1 & 0.1449 & 0.0045 \\
\hline Phase S1-G & 0.1510 & 0.0034 & N1- Phase-S1 & 0.1189 & 0.0037 \\
\hline Phase T1-G & 0.1814 & 0.0035 & N1- Phase-T1 & 0.1154 & 0.0035 \\
\hline Phase T2-S2 & 0.1513 & 0.0047 & N1- Phase-G & 0.1541 & 0.0047 \\
\hline Phase S2-R2 & 0.1513 & 0.0047 & N1- Phase-N2 & 0.1310 & 0.0062 \\
\hline Phase R2-T2 & 0.1361 & 0.0042 & N1- Phase-R2 & 0.1290 & 0.0040 \\
\hline Phase R2-G & 0.1084 & 0.0033 & N1- Phase-S2 & 0.1173 & 0.0036 \\
\hline Phase S2-G & 0.1510 & 0.0034 & N1- Phase-T2 & 0.1143 & 0.0035 \\
\hline Phase T2-G & 0.1814 & 0.0035 & N2- Phase-R2 & 0.1449 & 0.0045 \\
\hline Phase T1-T2 & 0.1898 & 0.0049 & N2- Phase-S2 & 0.1189 & 0.0037 \\
\hline Phase T1-S2 & 0.1329 & 0.0041 & N2- Phase-T2 & 0.1154 & 0.0035 \\
\hline Phase T1-R2 & 0.1289 & 0.0040 & N2- Phase-G & 0.1541 & 0.0047 \\
\hline Phase S1-T2 & 0.1329 & 0.0041 & N2- Phase-R1 & 0.1290 & 0.0040 \\
\hline Phase S1-S2 & 0.1898 & 0.0049 & N2- Phase-S1 & 0.1173 & 0.0036 \\
\hline Phase S1-R2 & 0.1329 & 0.0041 & N2- Phase-T1 & 0.1143 & 0.0035 \\
\hline
\end{tabular}

By the the results of Equation 1, we can find the values of each capacitance element as given in Table 1. "R,S,T,N" indicated the conductor phase, whereas " 1,2 " indicated the line number. In example, phase T1-S1 indicated the capacitance value between phase $\mathrm{T}$ in line I and phase $\mathrm{S}$ in line I, Phase T2-S2 indicated the capacitance value between phase $\mathrm{T}$ in line II and phase $\mathrm{S}$ in line II, and so on. By the Table 1, the total values for capacitance in phase R1, S1, T1 respectively about $1.2213 \mu \mathrm{F}$, $1.1454 \mu \mathrm{F}, 1.1501 \mu \mathrm{F}$. Besides of the capacitance values, the inductance value for each phase in the model is defined by the Equation 2 and 3. By these equations we can find that the inductance value of 
each phase is about $73 \mathrm{mH}$. On the other hand, the resistance value of each phase in the model is about $0.35 \mathrm{ohm}$ which is defined by the Equation 4. Definition of symbols are given as follows

\subsection{Model Validation}

The model validation based on the voltage response from the simulation results to the real voltage response for each phase in line I and was performed when the DS were disconnected and the reactors in Substation A were opened. Figure 2(a) shows the validation result. The entire graphical image of this paper refers to system responses of voltage ( $\mathrm{kV}$ or $\mathrm{MV}$ ) versus time (s).

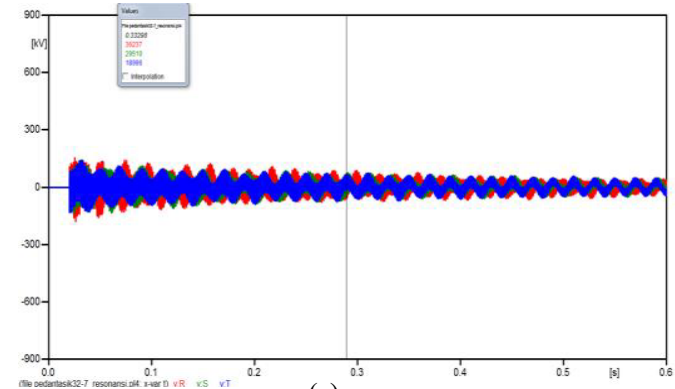

(a)

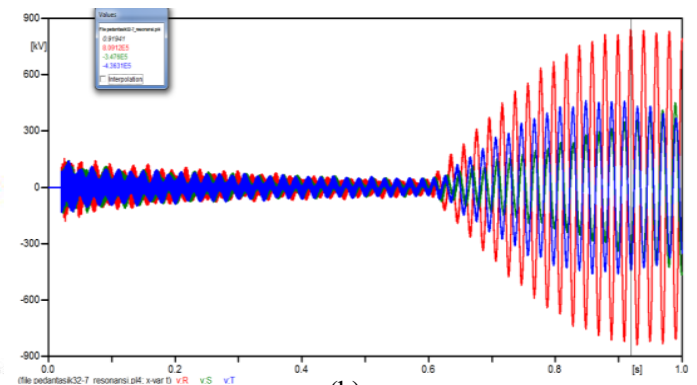

(b)

Figure 2. (a)Voltage response of each phase in line I Substation B based on model simulation when the reactors on Substation A is opened, (b) Simulation result of voltage value on Line 1 Substation B when the reactor is closed

On this validation, the voltage phase values of the simulation are $36.2 \mathrm{kV}, 29.5 \mathrm{kV}, 18.9 \mathrm{kV}$ for phases R1-N, S1-N, T1-N respectively. On the other hand the voltage values based on the real condition are $39.5 \mathrm{kV}, 26.8 \mathrm{kV}, 16.9 \mathrm{kV}$ respectively for phases R1-N, S1-N, T1-N. By these results we can find that the voltage response of model reaches the voltage value on the real condition, and then we can use the model for the further simulation.

\section{Simulations}

\subsection{Simulation when ES is Open, DS Closed, and Reactor in Substation A is Closed}

The simulation for voltage response when the reactor is closed is given by the figure 2(b). Reactive power (MVAR) value of the reactor is 100 MVAR for all the three phase therefore each phase has about 33.3 MVAR. By the MVAR value, the inductance per phase of the reactor can be determined, which each value is about $7910 \mathrm{mH}$ and $8320 \mathrm{mH}$ for neutral to ground. On this simulation, the voltage response for each phase is captured when the reactors in Substation A was closed. The voltage phase values of the simulation are $809 \mathrm{kV}, 347 \mathrm{kV}, 363 \mathrm{kV}$ for phases R1-N, S1-N, T1-N respectively. On the other hand the voltage values based on the real condition are $369 \mathrm{kV}, 62 \mathrm{kV}, 332 \mathrm{kV}$ respectively for phases R1-N, S1-N, T1-N. The results show that there are significant difference between the simulation and the real condition. Simulation results tend to higher then the value of the real condition because the real value is captured only on a moment data which can change if the captured time changed. However, even if the simulation value is greater, the model can shows that the reactor can affect the voltage response of each phase. The entry of reactor make the natural frequency of model reaches the operation frequency which is $50 \mathrm{~Hz}$. The significant increase of voltage values especially for phase R can be indicated as the cause of the broken line arrester.

\subsection{Simulation of Voltage Responses Related To the Single Pole Auto Reclose}


These simulations described the voltage value of the line if the transmission line facing the disturbance and try to performing reclose procedure. These simulations show the study of the impact of the reactor in Substation A. Figure 3(a) shows the voltage response when the reactor is opened and figure $3(\mathrm{~b})$ shows the voltage response when the reactor closed.
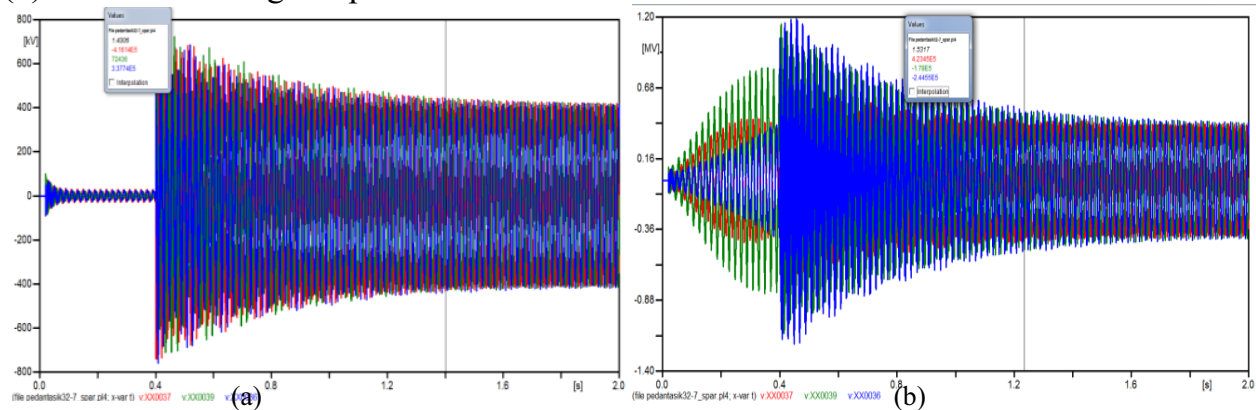

Figure 3. (a) Voltage Response on Line I Substation B without Reactor on Substation A, (b) Voltage Response on Line I Substation B with Reactor on Substation A

By the figure 3(a), the maximum voltage values for the R-N, S-N, T-N on the transients process respectively about $717 \mathrm{kV}, 664 \mathrm{kV}, 658 \mathrm{kV}$. But, for the steady state, the maximum voltage values for phase R-N, S-N, T-N is about $443 \mathrm{kV}, 443 \mathrm{kV}$, and $443 \mathrm{kV}$. Figure $3(\mathrm{~b})$ shows that the maximum voltage value for the R-N, S-N, T-N on the transients process respectively about $1126 \mathrm{kV}, 684 \mathrm{kV}$, $1180 \mathrm{kV}$. But, for the steady state, the maximum voltage value for phase R-N, S-N, T-N is about 423 $\mathrm{kV}, 454 \mathrm{kV}$, and $477 \mathrm{kV}$.

\section{Results}

\subsection{Resonance Phenomenon}

The entry of reactors in the Substation A can be the cause of the electrical resonance phenomenon which is related to the values of the reactors in the Substation A. The existing reactors in Substation A have been designed to compensate the capacitive value along the EHV transmission line from Substation A to Substation C which is about $304 \mathrm{~km}$. But, when the Substation B as a new substation intercepts the transmission line I of Substation A to Substation C in $105 \mathrm{~km}$ from Substation A, the inductive reactance value for each phase $7910 \mathrm{mH}$ reactor is about $2484 \Omega$, where as the total reactive capacitance for phase $\mathrm{R} 1(\mathrm{C}=1.2213 \mu \mathrm{F})$ is about $2608 \Omega$, for phase $\mathrm{S} 1(\mathrm{C}=1.1454 \mu \mathrm{F})$ is about 2781 $\Omega$, and for phase $\mathrm{T} 1(\mathrm{C}=1.1501 \mu \mathrm{F})$ is about $2769 \Omega$. These values show that the capacitive reactance value of each phase in the transmission line from Substation A to Substation B reaches the inductive reactance values of this system which can cause the electrical resonance phenomenon.

This electrical resonance increases the voltage value for each phase of the transmission line especially for phase $\mathrm{R}$ which is the voltage maximum value increased until the $809 \mathrm{kV}$. The voltage exceeds the voltage value of the line arrester in Substation B which has the nominal voltage about 444 $\mathrm{kV}$. Since this voltage needs to be neutralized to the ground through the line arrester, the phase $\mathrm{R}$ line arrester in Substation B experienced the excessive heating process until it broken.

\subsection{Single Pole Auto Reclose (SPAR)}

The entry of reactor with inductance $7910 \mathrm{mH}$ per phase and $8340 \mathrm{mH}$ neutral to ground in Substation A affect the voltage values in line I at Substation B. The maximum voltage value for each phase increase significantly especially for phase T-N increased until $1180 \mathrm{kV}$.

Maximum voltage value for steady state condition when the reactor in Substation A is opened is about $443 \mathrm{kV}$ for phase R-N, $443 \mathrm{kV}$ for phase $\mathrm{S}-\mathrm{N}, 443 \mathrm{kV}$ for phase $\mathrm{T}-\mathrm{N}$. The steady state value is 
defined as the time about $0.9 \mathrm{~s}$ after the disturbance. However, if the reactor is closed in Substation A, the maximum voltage value in the steady state condition is about $423 \mathrm{kV}$ for phase $\mathrm{R}-\mathrm{N}, 454 \mathrm{kV}$ for phase S-N, $477 \mathrm{kV}$ for phase T-N.

If we compare to the operation voltage value at $500 \mathrm{kV}$ line to line (or maximum $408 \mathrm{kV}$ line to neutral), the difference voltage value (at Substation A and Substation B) for each phase without reactor is stay in the normal operation range for the auto reclose procedure. But in the other hand, the entry of reactor makes the maximum difference voltage value exceed the operation range for auto reclose. Based on the data setting of the protection relay, the maximum acceptable voltage different value in both side Substation A and Substation B is about $10 \%$ from the nominal value. Therefore for the $500 \mathrm{kV}$ operation voltages, the maximum acceptable for voltage difference value is about $50 \mathrm{kV}$. Based on these results, the EHV transmission line from Substation A to Substation B is potential to success in reclose process if the reactor is opened. But, if the reactor is closed, the reclose process is potentially failed. Besides on that, the entry of rector in Substation A potentially broke the line arrester, because there is a phase with transient voltage until $1180 \mathrm{kV}$ which exceeds the nominal operation voltage for line arrester.

\section{Conclusions and Recommendation}

The model and simulation for the EHV transmission line from Substation A to Substation B is able to demonstrate the electrical resonance phenomena which significantly increase the voltage values for each phase in de-energized line. The resonance is triggered by the presence of reactor in Substation A and the capacitive and inductive reactance along the transmission line from Substation A to Substation B which match the resonance frequency of this system. Furthermore, electrical resonance phenomenon will potentially fail the auto recloses procedure which needs recalculation and resetting of reactor parameter to avoid this phenomenon. As recommendation for the further work, recalculation of the inductance value of the reactor is a key important to avoid the electrical resonance on the transmission line.

\section{References}

1. B. Filipović-Grčić, A. Župan, I. Uglešić, D. Mihalic, D. Filipović-Grčić, "Transients Caused by Switching of $420 \mathrm{kV}$ Three-Phase Variable Shunt Reactor", Paper submitted to the International Conference on Power Systems Transients (IPST2015) in Cavtat, Croatia June 15-18, 2015.

2. D. A. N. Jacobson, L. Marti, R. W. Menzies, "Modeling Ferroresonance in a $230 \mathrm{kV}$ Transformer-Terminated Double-Circuit Transmission Line", IPST '99 International Conference on Power Systems Transients, June 20-24, 1999, Budapest - Hungary.

3. Hazlee Azil Illias, Ab Halim Abu Bakar, Hazlie Mokhlis, Syahirah Abd Halim, "Calculation of Inductance and Capacitance in Power System Transmission Lines Using Finite Element Analysis Method”, PRZEGLĄD ELEKTROTECHNICZNY (Electrical Review), ISSN 0033-2097, R. 88 NR 10a/2012, 2012.

4. Kamlesh K. Wadhwani, "Simulation of Parallel Resonance Condition in Electrical Network Using EDSA", International Conference on, Computer Modeling and Simulation, pp. 708-713, 2008

5. M. Bradt, B. Badrzadeh, E. Camm, D. Mueller, J. Schoene, T. Siebert, T. Smith, M. Starke, R. Walling, "Harmonics and Resonance Issues in Wind Power Plants", Technical Paper.

6. Roger C. Dugan, "Examples of Ferroresonance in Distribution Systems", Technical Paper.

7. Salil S. Sabade, Himanshu J. Bahirat, Mythili Chaganti, Bruce A. Mork, "Shunt Reactor Switching Transients at High Compensation Levels", Technical Paper.

8. Tugay, Y, "10th International Conference on Electrical Power Quality and Utilisation, 2009. EPQU 2009”, 15-17 Sept. 2009, Lodz.

9. V. Valverde, A.J. Mazón, I. Zamora, G. Buigues, "Ferroresonance in Voltage Transformers: Analysis and Simulations", Technical Paper. 